\title{
Macrovascular complications and their associated risk factors in type 2 diabetic patients in Sana'a city, Yemen
}

A. Al-Khawlani, ${ }^{1}$ Z.A. Atef' and A. Al-Ansi ${ }^{1}$

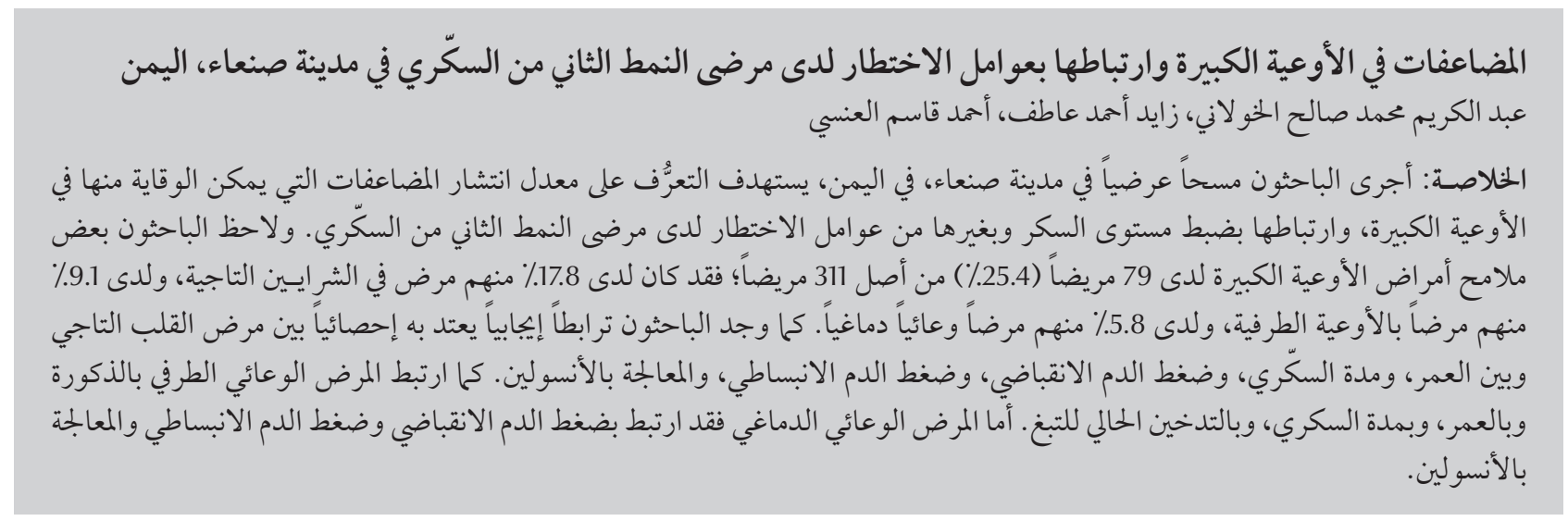

ABSTRACT A cross-sectional survey in Sana'a city, Yemen, aimed to determine the prevalence of preventable macrovascular complications and their association with glycaemic control and other risk factors in patients with type 2 diabetes mellitus (DM). Some features of macrovascular disease were found in 79 (25.4\%) of the 311 patients: $17.8 \%$ had coronary heart disease, $9.1 \%$ had peripheral vascular disease and $5.8 \%$ had cerebrovascular disease. Significant positive associations were found between coronary heart disease and age, duration of DM, systolic blood pressure, diastolic blood pressure and insulin treatment. Peripheral vascular disease was associated with male sex, age, duration of DM and current tobacco smoking. Cerebrovascular disease was associated with systolic blood pressure, diastolic blood pressure and insulin treatment.

Complications macrovasculaires et risques associés chez des patients souffrant de diabète de type 2 à Sanaa (République du Yémen)

RÉSUMÉ Une étude transversale réalisée à Sanaa (République du Yémen) avait pour objectif de déterminer la prévalence des complications macrovasculaires évitables et leur association avec le contrôle de la glycémie et d'autres facteurs de risque chez des patients souffrant de diabète de type 2. Sur 311 patients, 79 présentaient des signes de maladie macrovasculaire (soit 25,4\%) : 17,8 \% souffraient d'une cardiopathie coronarienne, 9,1\% d'une maladie vasculaire périphérique et 5,8\% d'une maladie cérébrovasculaire. Des associations positives significatives ont été constatées entre les cardiopathies coronariennes et l'âge, la durée du diabète de type 2 , la pression artérielle systolique, la pression artérielle diastolique et le traitement par insuline. La maladie vasculaire périphérique était associée au sexe masculin, à l'âge, à la durée du diabète de type 2 et la consommation de tabac au moment de l'étude. La maladie cérébrovasculaire était associée à la pression artérielle systolique, la pression artérielle diastolique et au traitement par insuline. 


\section{Introduction}

Diabetes mellitus (DM) is associated with a number of vascular complications. Microvascular complications such as retinopathy, nephropathy and neuropathy are specific to $\mathrm{DM}$, whereas macrovascular complications such as peripheral vascular disease (PVD), coronary heart disease (CHD) and cerebrovascular disease (CVD) can occur in the absence ofDM $[1,2]$.Macrovascular complications in DM consist mainly of an accelerated form of atherosclerosis that affects the coronary, carotid and peripheral arteries, thus increasing the risk of myocardial infarction, stroke and diabetic foot disease $[3,4]$. CHD has been associated with DM in numerous studies, notably the Framingham study [5]. More recent studies have shown that the risk of myocardial infarction in people with $\mathrm{DM}$ is equivalent to the risk in nondiabetic patients with a history of previous myocardial infarction [6].

These discoveries have lead to new recommendations by the American Diabetes Association and American Heart Association that DM be considered a coronary artery disease risk equivalent rather than a risk factor [7]. Patients with DM are 2 to 4 times more likely to develop cardiovascular diseases than the general population and have a 2-5-fold greater risk of dying from these diseases [7]. DM is also a strong independent predictor of the risk of stroke and CVD [8] and patients with type 2 DM have a 150\%-400\% higher risk of stroke [9]. Similarly, the risk of PVD in DM patients is 4 times higher than normal [10] and patients more commonly have infrapopliteal arterial occlusive disease and vascular calcification than nondiabetic cohorts [11]. DM is known to increase the risk of lower limb amputation by 15-40 times compared with the general population [9].

The prevalence of macrovascular complications among DM patients has not been studied in Yemen. Such data are important given that these complications account for approximately $50 \%$ of all deaths among DM patients in industrialized countries $[9,10]$. The aim of this study was to determine the prevalence of macrovascular complications in Yemeni patients with type $2 \mathrm{DM}$ and to identify the role of glycaemic control and other risk factors in patients with and without macrovascular complications.

\section{Methods}

This was a multi-centre, cross-sectional study, conducted from July 2006 to January 2007. The study was approved by the ethics committee of the Faculty of Medicine and Health Sciences at the University of Sana'a.

\section{Sample}

Patients aged $\geq 25$ years with type $2 \mathrm{DM}$ were recruited to the study when they visited one of the 2 primary care diabetes clinics in Sana' a city or visited the outpatient clinics at, or were admitted to, one of the 2 government hospitals (Al Thawra and Al-Kuwait) in the city. Patients who attend clinics in Sana'a, the capital city of Yemen, come from all regions of the country. Patients were invited to participate in the study by the physicians in the outpatient clinic and were examined according to the study protocol after they had given informed consent. Type 2 DM was diagnosed based on World Health Organization (WHO) criteria [12].Patientswhowere diagnosed with gestational diabetes, type $1 \mathrm{DM}$, ketonuria or autoimmune disease were excluded from the study.

\section{Data collection}

Demographic data and medical history were obtained by a personal interview and by review of the patient's medical records. Age, sex, duration of DM, type of treatment and family history of DM were recorded. Patients were also asked if they currently smoked tobacco (at least 10 cigarettes per day) or chewed khat leaves (daily).
The physicians took the patient's history of macrovascular complications by interviewing the patients using locally understood terms if necessary. A hospital discharge record was required to certify the event. PVD was diagnosed by manifestations of intermittent claudication, ulcers or gangrene or a history of amputation or when one or more foot pulses were absent during medical examination. CHD was diagnosed based on definitive myocardial infarction, ischaemic electrocardiographic changes (Q/QS and ST/T changes) and by a history of angina pectoris, myocardial infarction, coronary artery bypass graft or percutaneous coronary angioplasty. CVD was defined to include both a history of cerebral infarction or transient ischaemic attacks and was diagnosed on the basis of clinical manifestations and findings on computed tomography and a positive answer to the question "Have you ever had a stroke?" Patients with cerebral haemorrhage and embolism originating from cardiac thrombi were excluded from this study.

Blood pressure was measured on the right arm, with the subject seated after 10 minutes rest, using a standard clinical mercury sphygmomanometer with an appropriate cuff size. Hypertension was diagnosed according to WHO criteria [13] if systolic pressure was $\geq 140 \mathrm{mmHg}$ or diastolic pressure $\geq 90 \mathrm{mmHg}$ or if the patient was taking antihypertensive drugs.

Height and weight were recorded with the patient wearing clothing and without shoes. Body mass index (BMI) was defined as weight $(\mathrm{kg}) /$ height $^{2}$ $\left(\mathrm{m}^{2}\right)$. Obesity was classified according to WHO criteria [14].

Blood was drawn after overnight fasting for determination of the levels of fasting plasma glucose, glycosylated haemoglobin (HbAlc) and the lipid profile. A second venous blood sample was taken 2 hours later, to determine the 2-hour postprandial glucose. All biochemical measurements were carried out on the same day as blood collection 
using standard laboratory automated techniques. Plasma glucose level was assessed by means of the glucose hexokinase method (Roche Diagnostic, Mannheim, Germany). Serum total cholesterol, high-density lipoprotein (HDL) and low-density lipoprotein (LDL) cholesterol and serum triglycerides were measured using enzymatic techniques (Boehringer-Mannheim, Germany). Low-density lipoprotein (LDL) cholesterol was calculated using the Friedewald equation.

The cut-offs were as follows: fasting plasma glucose $<126 \mathrm{mg} / \mathrm{dL}$, 2-hour postprandial glucose $<140 \mathrm{mg} / \mathrm{dL}$, total cholesterol $>200 \mathrm{mg} / \mathrm{dL}$, triglycerides $>150 \mathrm{mg} / \mathrm{dL}$, HDL cholesterol < 40 $\mathrm{mg} / \mathrm{dL}$ and LDL cholesterol $>150 \mathrm{mg} /$ $\mathrm{dL}[12,15]$.

$\mathrm{HbAlclevel}<7 \%$ was taken to indicate good glycaemic control.

\section{Statistical analysis}

Statistical analysis was performed using SPSS software, version 15. Mean and standard deviation (SD) were determined for quantitative data. Student $t$-test was conducted to determine the significance of observed difference between the means of clinical parameters of males and females. Chi-squared tests were used to ascertain the association between macrovascular disease and clinical variables. $P<0.05$ was considered significant.

\section{Results}

\section{Patients' background characteristics}

A total of 311 patients with type $2 \mathrm{DM}$ were studied. There were 155 males (49.8\%) and 156 females (50.2\%), mean age 53.9 (SD 10.9) years (range 25-85 years). The duration of DM varied between $1-35$ years. Of the total patients $53.4 \%$ had hypertension [150 (48.2\%) systolic hypertension and 97 (31.2\%) diastolic hypertension]. The mean BMI was 24.1 (SD 4.1$) \mathrm{kg} / \mathrm{m}^{2}$, and the prevalence of overweight (BMI $\left.>25-<30 \mathrm{~kg} / \mathrm{m}^{2}\right)$ was $34.1 \%$ and of obesity (BMI $\left.>30 \mathrm{~kg} / \mathrm{m}^{2}\right)$ was $8.7 \%$. HbAlc levels showed that 211 (87.9\%) had poor glycaemic control (HbAlc $\geq 7 \%$ ).

DM was being treated with diet alone for 29 patients (9.3\%), with oral hypoglycaemic agents for 227 (72.9\%) and with insulin in the remaining 55 (17.7\%). Table 1 showed the characteristic of the DM patients by type of treatment. Insulin-treated patients had a significantly longer duration of disease than individuals on diet or oral hypoglycaemic therapy $(P<0.001)$. Patients on insulin therapy had a higher prevalence of CHD and PVD compared with patients under oral hypoglycaemic therapy and diet alone, but the difference was only significant for CHD $(P<0.006)$. Patients on oral hypoglycaemic therapy had a significantly higher prevalence of CVD compared with patients on insulin therapy or controlled with diet alone $(P<0.037)$.

Table 2 shows the demographic, clinical and laboratory findings for the total sample and for males and females. Overall 79 (25.4\%) DM patients had symptoms of macrovascular complications: 28 (9.1\%) had PVD, 55 (17.8\%) had CHD and 18 (5.8\%) had CVD. Two patients had all 3 types of macrovascular complication, 10 patients had both PVD and CHD, 11 patients had CHD and CVD and 3 patients had PVD and CVD. The prevalence of PVD was significantly higher in men than women $(14.1 \%$ versus $8.8 \%, P<0.001)$ but there was no significant difference between males and females in the prevalence of CVD (6.5\% versus 5.1\%, $P=0.07)$ or $\mathrm{CHD}(20.6 \%$ versus $14.7 \%$, $P=0.17)$. Overall $21.2 \%$ of patients reported being current cigarette smokers and $50.8 \%$ chewed khat leaves daily. Significantly more men than women were smokers $(P=0.005)$ and $k$ hat users $(P<0.001)$.

\section{Relationship between DM and macrovascular complications}

The clinical parameters of patients in each subgroup of macrovascular disease-PVD, CHD and CVD_were compared with those without the condition (Tables 3-5).

The significant predictive risk factors for PVD were male sex $(P<0.001)$, age

\begin{tabular}{|c|c|c|c|c|c|c|c|}
\hline \multirow[t]{2}{*}{ Variable } & \multicolumn{2}{|c|}{$\begin{array}{l}\text { Insulin } \\
(n=55)\end{array}$} & \multicolumn{2}{|c|}{$\begin{array}{c}\text { Oral hypoglycaemic } \\
\text { agents } \\
(n=227)\end{array}$} & \multicolumn{2}{|c|}{$\begin{array}{l}\text { Diet alone } \\
\quad(n=29)\end{array}$} & \multirow[t]{2}{*}{$P$-value } \\
\hline & Mean & SD & Mean & SD & Mean & SD & \\
\hline Age (years) & 55.8 & 9.3 & 53.3 & 11.2 & 55.6 & 11.0 & 0.22 \\
\hline \multirow[t]{2}{*}{ Duration of DM (years) } & 11.9 & 7.3 & 5.1 & 5.5 & 4.9 & 7.1 & $<0.001^{\mathrm{a}}$ \\
\hline & No. & $\%$ & No. & $\%$ & No. & $\%$ & \\
\hline Peripheral vascular disease & 7 & 12.0 & 18 & 7.9 & 3 & 10.3 & $0.51^{\mathrm{b}}$ \\
\hline Coronary heart disease & 16 & 29.0 & 37 & 16.3 & 2 & 6.9 & $0.006^{\mathrm{b}}$ \\
\hline Cerebrovascular disease & 1 & 1.8 & 17 & 7.5 & 0 & 0.0 & $0.037^{b}$ \\
\hline
\end{tabular}

${ }^{a}$ ANOVA test; ${ }^{b}$ Chi-squared test.

$S D=$ standard deviation . 


\begin{tabular}{|c|c|c|c|c|c|c|c|}
\hline \multirow[t]{2}{*}{ Variable } & \multicolumn{2}{|c|}{$\underset{(n=311)}{\text { All }}$} & \multicolumn{2}{|c|}{$\begin{array}{c}\text { Males } \\
(n=155)\end{array}$} & \multicolumn{2}{|c|}{$\begin{array}{l}\text { Females } \\
(n=156)\end{array}$} & \multirow[t]{2}{*}{$\begin{array}{c}P \text {-value } \\
\text { (males vs females) }\end{array}$} \\
\hline & Mean & SD & Mean & SD & Mean & SD & \\
\hline Age (years) & 53.9 & 10.9 & 54.7 & 11.7 & 53.2 & 10.0 & 0.20 \\
\hline Duration of DM (years) & 6.3 & 6.5 & 6.2 & 6.9 & 6.4 & 6.1 & 0.76 \\
\hline $\mathrm{BMI}\left(\mathrm{kg} / \mathrm{m}^{2}\right)$ & 24.1 & 4.1 & 24.1 & 4.2 & 24.3 & 4.0 & 0.61 \\
\hline \multicolumn{8}{|l|}{ Glycaemic profile } \\
\hline Fasting blood glucose (mg/dL) & 211.1 & 89.5 & 205.3 & 85.5 & 216.7 & 93.0 & 0.25 \\
\hline $\begin{array}{l}\text { 2-hour postprandial blood glucose } \\
\text { (mg/dL) }\end{array}$ & 311.2 & 110.9 & 306.9 & 111.5 & 315.4 & 110.6 & 0.50 \\
\hline HbAlc (\%) & 9.5 & 2.2 & 9.3 & 1.9 & 9.7 & 2.4 & 0.153 \\
\hline \multicolumn{8}{|l|}{ Lipid profile } \\
\hline Total cholesterol (mg/dL) & 189.2 & 49.1 & 188.0 & 48.5 & 189.8 & 49.9 & 0.82 \\
\hline HDL cholesterol (mg/dL) & 42.3 & 28.8 & 41.7 & 27.7 & 42.8 & 25.8 & 6.70 \\
\hline LDL cholesterol (mg/dL) & 142.2 & 43.2 & 141.1 & 42.4 & 143.2 & 451.9 & 0.67 \\
\hline \multirow[t]{2}{*}{ Triglycerides (mg/dL) } & 222.5 & 116.9 & 233.1 & 127.9 & 212.1 & 104.4 & 0.12 \\
\hline & No. & $\%$ & No. & $\%$ & No. & $\%$ & \\
\hline \multicolumn{8}{|l|}{ Macrovascular disease } \\
\hline Peripheral vascular disease & 28 & 9.1 & 22 & 14.1 & 6 & 8.8 & $<0.001$ \\
\hline Coronary heart disease & 55 & 17.8 & 32 & 20.6 & 28 & 14.7 & 0.17 \\
\hline Cerebrovascular disease & 18 & 5.8 & 10 & 6.5 & 8 & 5.1 & 0.07 \\
\hline \multicolumn{8}{|l|}{ Hypertension } \\
\hline Systolic hypertension & 150 & 48.2 & 71 & 47.3 & 79 & 52.7 & 0.31 \\
\hline Diastolic hypertension & 97 & 31.2 & 47 & 48.5 & 50 & 51.6 & 0.74 \\
\hline \multicolumn{8}{|l|}{ Smoking/substance use } \\
\hline Smokes tobacco & 66 & 21.2 & 43 & 27.7 & 28 & 14.7 & 0.005 \\
\hline Chews khat daily & 158 & 50.8 & 100 & 64.5 & 58 & 37.2 & $<0.001$ \\
\hline \multicolumn{8}{|l|}{ Family history } \\
\hline Family history of DM & 188 & 50.8 & 76 & 48.1 & 82 & 51.9 & 0.64 \\
\hline
\end{tabular}

$S D=$ standard deviation; $B M I=$ body mass index $; H b A 7 C=$ glycosylated haemoglobin; $H D L=$ high-density lipoprotein; $L D L=$ low-density lipoprotein .

$(P<0.004)$, duration of DM $(P<0.001)$ and smoking $(P<0.015)$ (Table 3$)$. The significant predictive risk factors for CHD were age $(P<0.001)$, duration of DM $(P<0.001)$, systolic blood pressure $(P<0.001)$, diastolic pressure $(P<0.002)$ and insulin treatment $(P$ $<0.021$ ) (Table 4). Mean systolic blood pressure $(P<0.028)$, diastolic blood pressure $(P<0.035)$ and the proportion of patients on insulin treatment $(P<0.037)$ were significantly higher in patients with CVD than those without it (Table 5). No significant associations were found for glycaemic control, BMI, total cholesterol, triglycerides, HDLcholesterol, LDL-cholesterol and khat use in any of the 3 categories of macrovascular disease.

\section{Discussion}

The present study investigated the prevalence and risk factors of macrovascular complications in a sample of Yemeni patients with type 2 DM. Little is known about the prevalence of DM in Yemen, except for a study in 2004 which found a prevalence of DM in the Yemeni population of $4.6 \%$ (7.4\% in males and 2.0\% in females) [16]. Our results strongly suggest that DM is associated with chronic macrovascular complications. The overall prevalence of macrovascular complications among Yemeni patients with type 2 DM was 25.4\%: $17.8 \%$ had a history of CHD, 9.1\% had evidence of PVD and 5.8\% were diagnosed with CVD.
The rates of macrovascular complications in type $2 \mathrm{DM}$ in the present study are consistent with the finding of other studies in the region. A study in the United Arab Emirates (UAE) found similar rates for total macrovascular disease (29.5\%), PVD (11.6\%), CHD (14.4\%) and CVD (3.5\%) [17]. In Saudi Arabia the prevalence of acute coronary syndrome (14.8\%) and myocardial infarction $(23.1 \%)$ were higher than our rate of CHD [18]. The rate of foot infection was $4.3 \%$ and amputation was $1.9 \%$; these results were lower than our rate for PVD, while the rate of stroke (10\%) was twice a high as our rate for CVD. In Bahrain the rate of PVD reported (11.8\%) is consistent with our results [19]. Compared with the rates reported 


\begin{tabular}{|c|c|c|c|c|c|}
\hline \multirow[t]{3}{*}{ Variable } & \multicolumn{4}{|c|}{ Peripheral vascular disease } & \multirow[t]{3}{*}{$P$-value } \\
\hline & \multicolumn{2}{|c|}{ Yes $(n=28)$} & \multicolumn{2}{|c|}{ No $(n=282)$} & \\
\hline & Mean & SD & Mean & SD & \\
\hline Age (years) & 59.5 & 9.4 & 53.4 & 10.6 & 0.004 \\
\hline Duration of DM (years) & 11.3 & 8.8 & 5.8 & 6.0 & $<0.001$ \\
\hline $\operatorname{BMI}\left(\mathrm{kg} / \mathrm{m}^{2}\right)$ & 23.1 & 3.8 & 24.3 & 4.1 & 0.13 \\
\hline HbA1c (\%) & 8.7 & 1.9 & 9.5 & 2.2 & 0.10 \\
\hline Total cholesterol (mg/dL) & 183.3 & 56.8 & 189.8 & 48.3 & 0.50 \\
\hline HDL cholesterol (mg/dL) & 42.2 & 28.6 & 42.3 & 25.5 & 0.99 \\
\hline LDL cholesterol (mg/dL) & 136.0 & 49.3 & 142.5 & 42.6 & 0.65 \\
\hline Triglycerides (mg/dL) & 284.5 & 112.7 & 24.3 & 117.5 & 0.57 \\
\hline Systolic blood pressure (mmHg) & 145.4 & 24.6 & 137.9 & 26.2 & 0.15 \\
\hline \multirow[t]{2}{*}{ Diastolic blood pressure $(\mathrm{mmHg})$} & 88.2 & 15.1 & 83.7 & 12.4 & 0.08 \\
\hline & No. & $\%$ & No. & $\%$ & \\
\hline Insulin treatment & 7 & 25.0 & 48 & 17.0 & 0.51 \\
\hline Smoking tobacco & 11 & 38.2 & 55 & 24.2 & 0.015 \\
\hline Chewing khat leaves & 18 & 64.3 & 140 & 49.6 & 0.14 \\
\hline Family history of DM & 13 & 40.4 & 144 & 51.1 & 0.64 \\
\hline
\end{tabular}

$S D=$ standard deviation; $B M I=$ body mass index $; H b A 7 c=$ glycosylated haemoglobin $; H D L=$ high-density lipoprotein; $L D L=$ low-density lipoprotein

by the London follow-up to the WHO multinational study of vascular disease in diabetics [20] the rate of CHD was 3 times lower in our study, the rate of CVD was similar and the rate of PVD was twice as high. In the United States of
America (USA), after a mean follow-up of 13 years, the prevalence of CHD in type 2 diabetics was $48.1 \%$, 3-fold higher than the prevalence in our study, and the prevalence of CVD (25.6\%) was several times higher than our rate [21]. The difference in our rate of macrovascular complications among patients with type 2 diabetes and the results mentioned above can be explained by the different study designs, differences in sample size and ethnic variations.

\begin{tabular}{|c|c|c|c|c|c|}
\hline \multirow[t]{3}{*}{ Variable } & \multicolumn{4}{|c|}{ Coronary heart disease } & \multirow[t]{3}{*}{$P$-value } \\
\hline & \multicolumn{2}{|c|}{ Yes $(n=55)$} & \multicolumn{2}{|c|}{ No $(n=254)$} & \\
\hline & Mean & SD & Mean & SD & \\
\hline Age (years) & 59.3 & 10.6 & 52.8 & 10.6 & $<0.001$ \\
\hline Duration of DM (years) & 9.8 & 7.8 & 5.5 & 5.9 & $<0.001$ \\
\hline $\mathrm{BMI}\left(\mathrm{kg} / \mathrm{m}^{2}\right)$ & 24.5 & 3.8 & 24.1 & 4.2 & 0.48 \\
\hline HbA1c (\%) & 9.1 & 2.2 & 9.6 & 2.2 & 0.23 \\
\hline Total cholesterol (mg/dL) & 184.7 & 52.4 & 190.1 & 48.5 & 0.46 \\
\hline HDL cholesterol (mg/dL) & 46.6 & 44.6 & 41.3 & 19.5 & 0.17 \\
\hline LDL cholesterol (mg/dL) & 142.8 & 42.9 & 142.0 & 43.4 & 0.91 \\
\hline Triglycerides (mg/dL) & 242.4 & 155.4 & 218.5 & 106.9 & 0.17 \\
\hline Systolic blood pressure (mmHg) & 149.1 & 28.9 & 136.3 & 25.5 & $<0.001$ \\
\hline \multirow[t]{2}{*}{ Diastolic blood pressure $(\mathrm{mmHg})$} & 89.0 & 15.6 & 83.1 & 11.8 & 0.002 \\
\hline & No. & $\%$ & No. & $\%$ & \\
\hline Insulin treatment & 16 & 20.1 & 88 & 15.0 & 0.02 \\
\hline Smoking tobacco & 12 & 21.8 & 54 & 21.3 & 0.93 \\
\hline Chewing khat leaves & 30 & 54.5 & 128 & 50.4 & 0.58 \\
\hline Family history of DM & 26 & 47.3 & 131 & 51.6 & 0.56 \\
\hline
\end{tabular}

$S D=$ standard deviation; $B M I=$ body mass index $; H b A 7 C=$ glycosylated haemoglobin; $H D L=$ high-density lipoprotein; $L D L=$ low-density lipoprotein . 


\begin{tabular}{|c|c|c|c|c|c|}
\hline \multirow[t]{3}{*}{ Variable } & \multicolumn{4}{|c|}{ Cerebrovascular disease } & \multirow[t]{3}{*}{$P$-value } \\
\hline & \multicolumn{2}{|c|}{ Yes $(n=18)$} & \multicolumn{2}{|c|}{ No $(n=292)$} & \\
\hline & Mean & SD & Mean & SD & \\
\hline Age (years) & 57.6 & 12.4 & 53.8 & 10.7 & 0.15 \\
\hline Duration of DM (years) & 9.1 & 4.3 & 6.2 & 6.6 & 0.33 \\
\hline $\mathrm{BMI}\left(\mathrm{kg} / \mathrm{m}^{2}\right)$ & 23.8 & 4.3 & 24.2 & 4.2 & 0.69 \\
\hline HbAlc level (\%) & 9.5 & 2.5 & 9.5 & 2.2 & 0.98 \\
\hline Total cholesterol (mg/dL) & 192.9 & 50.0 & 188.9 & 49.1 & 0.74 \\
\hline HDL cholesterol (mg/dL) & 42.6 & 19.2 & 42.3 & 26.1 & 0.95 \\
\hline LDL cholesterol (mg/dL) & 137.5 & 42.1 & 142.4 & 43.3 & 0.64 \\
\hline Triglycerides (mg/dL) & 255.6 & 165.1 & 220.5 & 113.4 & 0.22 \\
\hline Systolic blood pressure (mmHg) & 151.7 & 27.1 & 137.8 & 28.9 & 0.028 \\
\hline \multirow[t]{2}{*}{ Diastolic blood pressure (mmHg) } & 90.3 & 13.1 & 83.8 & 12.7 & 0.035 \\
\hline & No. & $\%$ & No. & $\%$ & \\
\hline Insulin treatment & 1 & 5.6 & 54 & 18.5 & 0.037 \\
\hline Smoking tobacco & 5 & 27.7 & 61 & 20.8 & 0.49 \\
\hline Chewing khat leaves & 10 & 55.5 & 148 & 50.7 & 0.69 \\
\hline Family history of DM & 8 & 44.4 & 149 & 51.0 & 0.59 \\
\hline
\end{tabular}

$S D=$ standard deviation; $B M I=$ body mass index $; H b A 7 c=$ glycosylated haemoglobin $; H D L=$ high-density lipoprotein; $L D L=$ low-density lipoprotein

Analysis of the risk factors in our study showed that systolic hypertension and diastolic hypertension were important risk factors for CHD and CVD, but not for PVD. Moreover, age and duration of DM were significantly associated with PVD and CHD, but not CVD. Smoking and male sex were significantly associated with PVD, while insulin treatment was significantly associated with CVD. These results are consistent with findings elsewhere in the Eastern Mediterranean Region (EMR). For example, in the UAE a cross-sectional study done to determine the prevalence and risk factors of macrovascular complications among diabetic patients revealed a significant association between macrovascular disease and male sex, age, duration of DM and hypertension [17]. A study in Pakistan showed that subjects with CHD were more likely to have hypertension and be current smokers, and that subjects who had experienced a cerbrovascular accident were more likely to have had DM for more than 5 years and to be current smokers [22]. In the Islamic Republic of Iran, a study revealed that the prevalence of $\mathrm{CHD}$ increased with age, BMI, smoking and insulin treatment [23].

Outside the EMR, in the USA, a study revealed that age, fasting glucose levels, smoking and triglyceride levels were independent risk factors for development of CHD events in type 2 DM, while age, hypertension, glucose and smoking predicted development of CVD [21]. Generally, in our results and the results of other studies mentioned above, the greatest risk factors for macrovascular complications were male sex, age, duration of DM and hypertension. We were not able to detect any association between the presence of macrovascular disease and glycaemic control as determined by $\mathrm{HbAlclevel}$. This negative correlation is not unique. Indeed, many longitudinal studies were unable to establish such a link $[20,24,25]$. The reason may be because ofthe relatively small sample size studied and the small number of patients with complications, or it may be related to the multi-factorial nature of macrovascular disease, as reported in other studies [26]. Furthermore, unlike experience elsewhere [27], our study was unable to demonstrate an association between BMI and dyslipidaemia in the study population, but this is not uncommon. For example, in Pakistan, macrovascular complications increased with age, duration of DM and were more prevalent in uncontrolled diabetics ( $\mathrm{HbAlc}>8.6 \%)$, but macrovascular complications were not associated with BMI or dyslipidaemia [28]. In Saudi Arabia, a study to determine the frequency of cardiovascular risk factors in Saudi and non-Saudi diabetics showed that hypertension, hyperlipidaemia and smoking were common CVD risk factors in both Saudis and non-Saudis, while obesity was less common in both groups. Both groups had poor blood glucose control [29].

Smoking was a significant risk factor for PVD but not for CHD or CVD. We also found no significant difference in the rate of macrovascular complications in patients chewing khat in any of the subgroups of CHD, PVD or CVD. Khat leaf chewing is widely practised in Yemen, especially among diabetics, who believe that it reduces blood sugar. Furthermore an association between 
khat chewing and hypertension has been reported previously [30].

The prevalence of CHD in ourstudy was rather low compared with studies in other geographical settings. This may be explained by the fact that patients in our study were slightly younger and had a lower rate of hypertension. The prevalence of overweight and obesity was considerably lower than the prevalence found in other studies in the region. For example, in a study in Riyadh, obesity was reported in $33 \%$ of adult diabetics [31] and in the UAE in 37\% [17]. In another study in Saudi Arabia, the mean age of the patients was 58.4 (SD 14.2) years, the prevalence of hypertension was $78 \%$ and the rates of overweight and obesity were $39.0 \%$ and $44.8 \%$ respectively [18]. In the Islamic Republic of Iran the study group had a mean age of
62.2 (SD 12.4) years and hypertension was present in $91 \%$ [32].

Other studies considered ethnic differences to explain the variation in the risk of cardiovascular disease between populations [33]. Among those, a USA-based study concluded that a substantial part of the risk associated with ethnicity can be attributed to socioeconomic status and geographical location rather than ethnicity [33]. The results of our study clearly demonstrate that DM is associated with chronic complications, including PVD, CHD and CVD in this sample of Yemeni diabetic patients. These findings highlight the need for primary care physicians to be aware of the possible presence of these complications among their patients. The general awareness of the community also needs to be raised about individual risk factors for DM and its complications.

\section{Conclusions}

$\mathrm{CHD}$ was the most frequent macrovascular complication in this group of type 2 DM patients. The risk was relatively low compared with that seen in patients in other geographical settings. Advanced age, duration of DM, male sex, hypertension, smoking and insulin treatment were the most significant risk factors for macrovascular complications in type 2 DM patients. In addition, a lack of correlation between macrovascular disease and glycaemic control was observed. Frequent screening of patients with type $2 \mathrm{DM}$ is desirable to identify patients at high risk of health complications and to prevent further disability.

\section{References}

1. Jarrett RJ. Type II (non-insulin-dependent) diabetes mellitus and coronary heart disease: chicken, egg, or neither. Diabetologia, 1984, 26:99-102.

2. Stern MP. Perspective in diabetes: diabetes and cardiovascular disease the "common soil" hypothesis. Diabetes, 1995, 44:369-374.

3. Duby JJ et al. Diabetic neuropathy: an intensive review. American Journal of Health-System Pharmacy, 2004, 61:160-173.

4. Porta M, Bandello F. Diabetic retinopathy: a clinical update. Diabetologia, 2002, 45:1617-1634.

5. Kannel WB, McGee DL. Diabetes and cardiovascular disease: the Framingham study. Journal of the American Medical Association, 1979, 241:2035-2038.

6. Haffnerr SM et al. Mortality from coronary heart disease in subjects with type II diabetes and non-diabetic subjects with and without myocardial infarction. New England Journal of Medicine, 1998, 339:279-234.

7. Buse JB et al. Primary prevention of cardiovascular disease in people with diabetes mellitus: a scientific statement from the American Heart Association and the American Diabetes Association. Diabetes Care, 2007, 30:162-172.

8. Letho $\mathrm{S}$ et al. Predictors of stroke in the middle-aged patients with non-insulin dependent diabetes. Stroke, 1996, 27:63-88.

9. Beckman JA, Creager MA, Libby P. Diabetes and atherosclerosis: epidemiology, pathophysiology, and management. Journal of the American Medical Association, 2002, 287:2570-2581.

10. Tan MH, MacLean DR. Epidemiology of diabetes mellitus in Canada. Clinical and Investigative Medicine, 1995, 18:240-246.

11. Jude EB et al. Peripheral arterial disease in diabetic and nondiabetic patients. Diabetes Care, 2001, 24:1433-1437.

12. Alberti KG MM, Zimmet PZ. Definition, diagnosis and classification, of diabetes mellitus. Geneva, World Health Organization, 1999.
13. 1999 World Health Organization-International Society of Hypertension Guidelines for the Management of Hypertension. Guidelines Subcommittee. Journal of Hypertension, 1999, 17:151-183.

14. Obesity: preventing and managing the global epidemic. Report of a WHO consultation on obesity. Geneva, World Health Organization, 1998.

15. Executive Summary of Third Report of the National Cholesterol Education Program (NCEP) Expert Panel on Detection, Evaluation, and Treatment of High Blood Cholesterol in Adults (Adult Treatment Panel III). Journal of the American Medical Association, 2001, 285(19):2486-2487.

16. Al-Habori M, Al-Mamari M, Al-Meeri A. Type Il diabetes mellitus and impaired glucose tolerance in Yemen: prevalence, associated metabolic changes and risk factors. Diabetes Research and Clinical Practice, 2005, 65:275-281.

17. Al-Maskari F, El-Sadig M, Norman JN. The prevalence of macrovascular complications among diabetic patients in the United Arab Emirates. Cardiovascular Diabetology, 2007, 6:24 (doi: 10.1186/1475-2840-6-24).

18. Al-Wakeel JS et al. Diabetes complications in 1952 type II diabetes mellitus managed in a single institution. Annals of Saudi Medicine, 2008, 28(4):260-266.

19. Al-Mahroos F, Al-Roomi K. Diabetic neuropathy, foot ulceration, peripheral vascular disease and potential risk factors among patients in Bahrain: a nationwide primary care diabetes clinic-based study. Annals of Saudi Medicine, 2007, 27(1):25-31.

20. Morrish NJ et al. Risk factors for macrovascular disease in diabetes mellitus: the London follow-up to the WHO multinational study of vascular disease in diabetics. Diabetologia, 1991, 34(8):590-594.

21. Abu-Lebdeh HS, Hodge DO, Nguyen TT. Predictors of macrovascular disease in patients with type 2 diabetes mellitus. Mayo Clinic Proceedings, 2001, 76(7):707-712 
22. Khuwaja AK et al. Macrovascular complications and their associated factors among persons with type II diabetes in Karachi, Pakistan-a multi-center study. Journal of the Pakistan Medical Association, 2004, 54(2):60-66.

23. Janghorbani M, Amini M, Tavassoli A. Coronary heart disease in type II diabetes mellitus in Isfahan, Iran: prevalence and risk factors. Acta Cardiologica, 2006, 61(1):13-20.

24. Park K. Park's textbook of preventive and social medicine. Jabalpur, India, Banarasidas Bhanot Publishers, 2002.

25. UK Prospective Diabetes Study Group. Tight blood pressure control and risk of macrovascular and microvascular complications in type II diabetes: UK PDS 38. British Medical Journal, 1998, 317:703-713.

26. Nazimek-Siewniak B, Moczulski D, Gieszczak W. Risk of macrovascular and microvascular complications in type II diabetes results of longitudinal study design. Journal of Diabetes Complications, 2002, 16:271-276.

27. Lubree HG et al. Body fat and cardiovascular risk factors in Indian men in three geographical locations. Food and Nutrition Bulletin, 2002, 23:146-149.
28. Hashim R et al. Prevalence of macrovascular complication in diabetics of WAH, District Rowalpindi. Journal of the Pakistan Medical Association, 1999, 49(1):8-11.

29. Akbar DH, Ahmed MM, Algamdi AA. Cardiovascular risk factors in Saudi Arabian and Non Saudi Arabian diabetic patients in Saudia Arabia. Eastern Mediterranean Health Journal, 2003 9(5-6):884-892.

30. Hassan NAGM et al. Qat chewing and arterial blood pressure. A randomised controlled clinical trial of selective alpha-1 and beta-1 adrenoceptor blockades. Saudi Medical Journal, 2005, 26:537- 541.

31. El Hazmi MA, Warsy AS. Prevalence of overweight and obesity in diabetic and non-diabetic Saudis. Eastern Mediterranean Health Journal, 2000, 6(2-3):276-282.

32. Esteghamati et al. Prevalence of diabetes and other cardiovascular risk factors in an Iranian population with acute coronary syndrome. Cardiovascular Diabetology, 2006, 5:15 (doi: 10.1186/1475-2840-5-15)

33. Matthews KA et al. Ethnic Differences in cardiovascular burden among middle-aged women's, health across the nation. American Heart Journal, 2005, 149:1066-1072.

\section{Second Annual Conference of the Global Diabetes Alliance (GDA 2), Cairo, Egypt, 26-29 October, 2010}

Cairo will host the second Global Diabetes Alliance Congress, a very special event whose goal is to unify protocols for epidemiological surveys and prevention and management of diabetes and its related disorders. This Congress will be dedicated to the presentation of updates on the diabetes epidemic in various parts of the world (including the Middle East and Africa) and workshops designed to initiate collaborative research projects among groups of investigators throughout the world. The programme can be accessed from the conference website at: http://conf.global-diabetes. org/index.htm 